\title{
DEONTOLOGY OF FRENCH JOURNALISM IN CONTEMPORARY POLITICAL CONTEXT
}

\author{
M.V. Tarasova \\ Moscow State Institute of International Relations (University), \\ 76 Vernadsky Ave., Moscow, 119454, Russia
}

\begin{abstract}
In the focus of the article are different views of French media representatives on the appropriateness of the Council for Deontology and Mediation, founded in France in December 2019. The Council positions itself as an independent structure that carries out the functions of self-regulation (within the profession), and co-regulation (between journalists and audience) in the field of mass media based on French and international codes of journalism ethics. The Council considers mass media audience complaints about journalists' violation of professional ethics and acts as an intermediary in resolving information disputes between journalists, publishers and the audience.

The main goal of the Council on Deontology and Mediation is to restore the audience's trust in mass media and create a culture of honest journalism. However, its establishment and activities provoked a fierce debate in the French journalism community, splitting it into two camps. The opponents, who happened to be in the majority, do not recognize the legitimacy of the Council and refuse to work with it.

In this respect, the article examines the following issues: a brief history of French and international codes of journalism ethics; the reasons of the crisis of trust to traditional media; the political context in which the Council for Deontology and Mediation emerged; the Council's structure and functions; arguments put for and against its activities; analysis of two cases that illustrate its activities.

The article is based on materials taken from traditional French media: Le Monde, Le Figaro, Libération, Les Échos, L'Express, La Croix; online media: Médiapart and Contexte, as well as TV interviews with media representatives.
\end{abstract}

Key Words: deontology of journalism, codes of journalism ethics, a crisis of trust to traditional mass media, the Council for Deontology and Mediation

For citation: Tarasova M.V. (2021). Deontology of French Journalism in Contemporary Political Context. Philology at MGIMO, 7(3), pp. 97-105. https://doi.org/10.24833/2410-2423-2021-3-27-97105 


\title{
ДЕОНТОЛОГИЯ ФРАНЦУЗСКОЙ ЖУРНАЛИСТИКИ В СОВРЕМЕННОМ ПОЛИТИЧЕСКОМ КОНТЕКСТЕ
}

\author{
M.B. Тарасова \\ Московский государственный институт международных отношений (университет) МИД России, \\ 119454, Россия, Москва, пр. Вернадского, 76
}

\begin{abstract}
Аннотация. Статья посвящена обзору точек зрения представителей франиузских СМИ по поводу иелесообразности создания и функиионирования Совета по деонтологии и медиаиии, учреждённого во Франиии в декабре 2019 года. Этот орган позиционирует себя как независимая структура, осуществляющая саморегулирование (внутри профессии), и сорегулирование (между журналистами и аудиторией) в сфере массовой информации, опираясь при этом на наииональные и международные кодексы журналистской этики. Совет рассматривает жалобы аудитории средств массовой информации на нарушение журналистом профессиональной этики, а также выступает посредником при разрешении информационных споров между журналистами, издателями и аудиторией.

Главная иель Совета по деонтологии и медиации - восстановление доверия аудитории к СМИ и формирование культуры честной журналистики. Между тем, создание и деятельность этого органа вызвали острую полемику во франиузском журналистском сообществе, расколов его на два лагеря. Противники, которых оказалось большинство, не признают легитимность Совета и отказываются с ним сотрудничать.

В этой связи в статье рассматриваются следующие вопросы: краткая история создания кодексов этики франиузской и международной журналистики; причины кризиса доверия к традиицонным СМИ; политический контекст, в котором появился Совет по деонтологии и медиаиин; его структура и функиии; аргументы, выдвигаемые за и против его деятельности; анализ двух кейсов, иллюстрирующих его деятельность.

Материалом для анализа послужили статьи, взятые из франиузских традииионных СМИ: Le Monde, Le Figaro, Libération, Les Échos, L’Express, La Croix, из интернет-изданий: Ме́diapart и Contexte, а также телевизионные интервью с представителями СМИ.
\end{abstract}

Ключевые слова: деонтология журналистики, кодекс профессиональной этики журналиста, кризис доверия к традиционным СМИ, Совет по деонтологии и медиации

Для цитирования: Тарасова М.В. (2021). Деонтология французской журналистики в современном политическом контексте. Филологические науки в МГИМО. 7(3), С. 97-105. https:/doi. org/10.24833/2410-2423-2021-3-27-97-105

\section{Введение}

$\mathrm{O}$ бучение на факультетах международной журналистики российских вузов включает в себя курс «Французская журналистика», который знакомит студентов со средствами массовой информации и медиакультурой Франции. К числу важных понятий, которые изучают будущие журналисты, относится понятие «деонтология».

В журналистике, как и в любой другой профессии, существуют этические стандарты. Они касаются всех этапов журналистской деятельности, начиная со сбора, обработки информации (редак- 
тирования и комментирования) и заканчивая её распространением. Эти нормы зафиксированы в национальных и международных кодексах профессиональной этики журналиста. Этический кодекс, по мнению исследователя прикладной этики В.И. Бакштановского, с одной стороны, служит ориентиром в мире нравственных ценностей, мотивирует самоопределение журналиста, побуждает к нравственной рефлексии, а с другой - представляет собой набор критериев для оценки журналистской деятельности «со стороны» [1, с.195].

Во Франции разработка деонтологии журналистики имеет давние традиции. Между тем, несмотря на существование национальных и международных кодексов профессиональной этики, в стране не было органа, который следил бы за соблюдением этических норм и указывал бы на случаи их нарушения журналистами. В декабре же 2019 года такой орган был учреждён: это Совет по деонтологии и медиации. По замыслу его создателей, он призван восстановить доверие аудитории к СМИ и способствовать формированию качественной журналистики. Однако, против всех ожиданий, появление такого Совета вызвало раскол в журналистском сообществе, разделив его на два лагеря.

В самом деле, деонтология журналистики - это миф или реальность? Возможно ли в современном мире, где скорость подачи информации превалирует над её качеством, где журналисты, в погоне за сенсацией, часто забывают о моральных нормах, говорить о единой профессиональной этике для всех видов СМИ? Способен ли, наконец, Совет по деонтологии и медиации вернуть доверие аудитории к журналистам?

Обзору точек зрения экспертов и представителей французских СМИ по этим вопросам и посвящена наша статья.

\section{Краткая история вопроса}

Франция стала первой европейской страной, в которой была разработана деонтология журналистики. И это неслучайно: в период Первой мировой войны профессиональная деятельность журналистов подвергалась жесточайшей цензуре. Поэтому в 1918 году Национальный профсоюз французских журналистов принимает Кодекс профессиональных обязанностей журналиста (Charte des devoirs professionnels des journalistes).

В 1938 году этот документ претерпел ряд изменений. Впоследствии он был положен в основу Декларации прав и обязанностей журналиста (Déclaration des devoirs et des droits des journalistes), которая была принята в 1971 году в Мюнхене профсоюзами журналистов нескольких европейских стран: Франции, Германии, Бельгии, Италии, Люксембурга и Нидерландов. И именно этот документ стал ориентиром для мировых СМИ в области деонтологии профессии.

В 2011 году Национальный профсоюз французских журналистов переименовывает «Кодекс профессиональных обязанностей журналиста» в «Кодекс профессиональной этики журналиста» (Charte d'éthique professionnelle des journalistes) и добавляет туда пункт о защите источника информации, полученной конфиденциально [2, с. 57].

12 июня 2019 года на XXX-ом Всемирном конгрессе в Тунисе Международная Федерация журналистов приняла Глобальную хартию журналистской этики (La Charte déthique mondiale des journalistes), которая дополнила Декларацию принципов поведения журналиста (1954г.), известную как «Декларация Бордо». Глобальная хартия журналистской этики опирается на Всеобщую декларацию прав человека, провозглашающую право каждого человека на доступ к информации, которое является основой журналисткой деятельности. Хартия содержит преамбулу и 16 статей, в которых определяются права и обязанности журналиста. В их числе есть, например, статья, которая говорит о том, что «ответственность журналиста перед общественностью преобладает над любой другой, в частности перед работодателями или представителями власти. Журналистика профессия, требующая времени, ресурсов и средств для достижения практических результатов, необходимых для её независимости» [13].

Помимо международных и национальных кодексов этики журналистов, существуют корпоративные кодексы, которые действуют внутри конкретного медиа-предприятия. В 80-е годы 
$\mathrm{XX}$ века многие газеты, радиостанции и телевизионные каналы приняли уставы, в которых нашли своё отражение редакционная политика, моральные ценности, регламент профессиональных взаимоотношений как внутри редакций, так и с аудиторией: читателями, слушателями и зрителями.

Несмотря на чёткий свод правил профессии, существуют факторы, которые могут поставить под удар их соблюдение, например, такие как: редакционная политика конкретного издания, давление руководства, погоня за сенсацией, получение информации любыми средствами, использование в работе непроверенных источников, конкуренция за право опубликовать новость первым [2, c. 59].

Важно отметить, что во Франции деонтологические нормы носят рекомендательный характер, поскольку они не закреплены юридически. Поэтому журналистов здесь крайне редко привлекают к ответственности или увольняют за нарушение профессиональной этики, в отличие от США, где случаи увольнения журналистов, к тому же без права заниматься профессией, - явление довольно частое.

К каким же последствиям может привести несоблюдение журналистами кодекса этических норм во Франции? Самое серьёзное - это потеря доверия аудитории, которая влечёт за собой потерю интереса к любой информации, исходящей от СМИ.

В настоящее время французские средства массовой информации переживают кризис, который усугубили события последнего года, связанные с пандемией. Опрос, проведённый в 2020 году институтом Кантар, показал, что уровень доверия к информации СМИ только за один год упал на 11 пунктов: ей доверяют всего лишь $24 \%$ французов. Причём это рекордно низкая цифра, начиная с 1987 года. В результате в рейтинге европейских стран Франция заняла предпоследнее место [9].

\section{Причины кризиса доверия к СМИ}

Доверие аудитории к медиа-информации, по мнению главы радиостанции France Info Винсента Жире, стало стремительно падать с начала протестов «жёлтых жилетов», чьи «агрессивные действия по отношению к журналистам навсегда останутся в исторической памяти редакций» [11]. Несмотря на невиданное по своему размаху освещение протестных акций «жёлтых жилетов» (20\% новостей при 14 часах ежедневного вещания в течение 5 месяцев), лидеры этого движения не были удовлетворены тем, как журналисты освещали уличные баталии и полицейский произвол. На этом основании «жёлтые жилеты» блокировали работу типографий, поджигали газетные киоски, скандировали под окнами редакций: «журналисты-коллаборационисты!», разбивали камеры журналистов, которые вели трансляции из гущи событий, а сами журналисты подвергались оскорблениям, угрозам и физическим нападениям. За полгода от протестных действий «жёлтых жилетов» пострадали 54 журналиста. Впервые в истории Франции государство было вынуждено защищать журналистов и выделять им охрану для передвижения в городе.

Чего же добились «жёлтые жилеты» своими действиями?

Во-первых, они вызвали шок и негодование у журналистского сообщества. Освещать протестные акции «жёлтых жилетов» стало «одним из самых тяжёлых испытаний профессии» [10]. В ответ на агрессию и оскорбления в адрес своих коллег, которые чаще других становились мишенью протестующих, национальный телевизионный канал BFM TV, на один день полностью отказался от трансляции протестных акций «жёлтых жилетов» [15].

Во-вторых, «жёлтые жилеты» подорвали доверие аудитории к СМИ, повторяя в прямом эфире, что журналисты неверно освещают события и потому им нельзя доверять.

Но существуют и другие причины снижения рейтинга доверия и интереса аудитории к традиционным СМИ. К ним относятся:

1) слишком большое количество информационных каналов, затрудняющее выбор;

2) низкое качество новостей, в том числе присутствие фейковых;

3) манера подачи информации, порождающая тревожность или раздражение и вызывающая желание переключиться на другой канал;

4) подражание СМИ друг другу, тиражирование одной и той же новости; 
5) неоправданная медиатизация некоторых информационных поводов;

6) и, наконец, появление сильных конкурентов традиционным СМИ: независимых альтернативных медиа, таких как Brut, Le Média, Thinkerview, Vécu, а также социальных сетей, которые стали главными источниками информации особенно для молодого поколения.

Проведённый редакциями анализ причин снижения доверия и интереса к информации побудил их пересмотреть принципы своей работы. Стало очевидно, что простое информирование перестало устраивать аудиторию, что возникла необходимость установить диалог с читателем, найти механизмы, которые вернули бы доверие и желание получать информацию не только на альтернативных медиа платформах, но и из традиционных СМИ.

В поисках путей выхода из кризиса редакции Radio France, La Croix, La Voix du Nord, L’Obs, L'Express, Reporters d'espoirs et Make.org решили объединить свои усилия и провести «гражданские консультации» с тем, чтобы в ходе диалога с аудиторией выработать новую концепцию журналистики, которая позволила бы восстановить доверие аудитории к СМИ.

С этой же целью в декабре 2019 года был создан Совет по деонтологии и медиации журналистов (Conseil de déontologie journalistique et de médiation). Попутно отметим, что такие Советы существуют уже в 18 странах Евросоюза. Первый из них появился в 1916 году в Швеции, а предпоследний - в 2009 году в Бельгии.

\section{Структура и функции Совета по деонтологии и медиации}

Совет состоит из трёх коллегий: журналисты, издатели и публика. В него вошли представители таких объединений, как:

- первый и старейший профсоюз журналистов (Le Syndicat national des journalistes (SNJ));

- $\quad$ профсоюзное объединение журналистов (L'Union syndical des journalistes (CFDT));

- $\quad$ международный альянс журналистов (L’Alliance internationale de journalistes (AIJ));

- коллективы журналистов и веб-изданий: «Informer n’est pas un délit», «Prenons la Une», «Profession Pigiste», «Contexte»;

- высшие школы журналистики: École supérieure de journalisme de Lille, École publique de Journalisme de Tours;

- $\quad$ пресс-клубы (des clubs de la presse);

- $\quad$ национальный профсоюз свободного радио (Syndicat national des radios libres);

- французская Федерация информагентств (Fédération française des agences de presse);

- $\quad$ национальная Федерация специализированной прессы (Fédération nationale de la presse d’information spécialisée);

- читательский клуб газеты Юго-Запад (Cercle des lecteurs de Sud-Ouest).

В своей деятельности Совет по деонтологии и медиации руководствуется уже приводимыми нами ранее документами: Кодексом профессиональной этики журналиста (1918/1938/2011, Франция); Мюнхенской декларацией прав и обязанностей журналиста (1971, Мюнхен) и Всемирным кодексом профессиональной этики журналиста (2019, Тунис).

Председатель Совета по деонтологии и медиации Патрик Эвено позиционирует его как «профессиональный орган, независимый от государства, который может провести проверку по собственной инициативе либо по жалобе зрителей, слушателей или читателей, если, по их мнению, в передаче или статье были нарушены этические нормы журналистики» [4]. В случае, если жалоба исходит от зрителя, слушателя или читателя, Совет назначает рабочую группу в составе трёх человек (une triplette): журналист, издатель и представитель общественности, которая её рассматривает и выносит заключение, которое Совет публикует на своём сайте и рекомендует «провинившемуся» СМИ опубликовать его на своём сайте.

Важно отметить, что Совет не является органом цензуры, поскольку выносит своё заключение уже после выхода в свет статьи, теле- или радиопередачи. Совет также «не уполномочен накладывать уголовные, финансовые или иные санкции. Мы не жандармы деонтологии», подчёркивает его председатель в своём интервью радиостанции Европа 1 [8]. 
Этот орган выступает, таким образом, в роли посредника и арбитра при разрешении споров между журналистами, издателями и аудиторией. Его цель состоит в формировании культуры честной журналистики и в восстановлении доверия к СМИ посредством диалога с аудиторией.

\section{Сильные стороны Совета по деонтологии и медиации}

Во-первых, он представляет собой инстанцию, которая на законном основании способна дать в публичном пространстве оценку действиям журналиста, нарушившего профессиональную этику, и вынести ему порицание.

Несмотря на существование национальных и международных кодексов профессиональной этики, а также редакционных уставов медиа-предприятий, до декабря 2019 года во Франции не было органа, который интерпретировал бы этические нормы и указывал бы на случаи их нарушения.

Представители Совета не отрицают, что помимо обоснованных жалоб на журналистов, есть и такие, например, которые исходят от лиц, не заинтересованных в независимых журналистских расследованиях, цель которых состоит в дискредитации конкретного журналиста. Поэтому Совет со всей тщательностью разбирается с каждым случаем и предаёт огласке необоснованные жалобы, что в итоге оборачивается против самих же дискредитаторов [6].

Во-вторых, Совет установил границу между медиа-информацией, соответствующей профессиональным нормам, и свободным выражением мыслей, которое, как любая игра без правил, не вписываясь в деонтологические рамки, повышает риск появления фейковых новостей и манипулирования общественным мнением.

В-третьих, Совет способствовал установлению диалога между всеми заинтересованными сторонами: издателями, от которых зависит выбор редакционной политики и экономической модели СМИ, профсоюзами журналистов, журналистскими коллективами независимых расследований, федерацией профессиональных издателей, информационными агентствами и членами гражданского общества.

\section{Совет по деонтологии и медиации - новый страж журналисткой этики?}

Несмотря на ряд преимуществ, которое получило журналистское сообщество в результате создания Совета по деонтологии и медиации, у него, тем не менее, оказалось больше противников, чем сторонников. Более двадцати СМИ отказались вступить в него: l'AFP, Challenges, Europe 1, L'Express, Le Figaro, Le Monde, Franceinfo TV, France 3 National, France Bleu, France Info, France Inter, LCI, Mediapart, L'Obs, Le Parisien, Le Point, TF1, La Tribune, TV5 Monde et 20 Minutes. В своём коллективном открытом письме, опубликованном на сайте Meдиапарm, представители этих изданий изложили причины своего отказа, одна из которых: политический контекст, в котором этот Совет был создан.

В самом деле, не прошло и полутора лет с момента избрания Эмманюэля Макрона президентом Французской Республики, как 22 декабря 2018 года был принят Закон о противодействии манипулированию информацией (Loi contre la manipulation de l'information), который в обществе известен как Закон о фейковых новостях (Loi infox), нарушающий, по мнению журналистов, Закон о свободе печати 1881 года. Дело в том, что новый закон позволяет в период выборов (президентских, парламентских или в Европарламент), вводить ускоренную процедуру, при которой судья в течение 48 часов может признать любую информацию ложной и привлечь за её распространителя к административной ответственности.

Этот же закон вменяет в обязанность интернет-платформам (Facebook, Twitter и др.) соблюдать принцип прозрачности, то есть указывать прямо, какие из материалов размещаются ими на коммерческой основе. Кроме того, по этому закону, Совет по телерадиовещанию может приостанавливать деятельность СМИ с участием иностранных государств или же государств, которые находятся под иностранным влиянием, если таковые распространяют «заведомо ложную информацию с целью повлиять на исход выборов» [12]. 
В результате на страницах французских СМИ развернулась острая полемика по поводу целесообразности функционирования Совета по деонтологии и медиации. Направленные против его деятельности аргументы можно свести к следующим:

1. Французские СМИ не нуждаются в такой инстанции, поскольку взаимоотношения СМИ и государства регламентируются Законом о свободе печати 1881 года, который гарантирует свободу в информировании граждан, декларирует права и обязанности СМИ и издателей, то есть обеспечивает правовую основу для публикаций. Совет же, по словам директора газеты «Фигаро» Марка Фёйе, «создаёт кодекс этического оценивания вне юридического поля» [14].

2. Совет по деонтологии и медиации не может считаться независимым органом ввиду того, что он был создан по инициативе государства и им же частично финансируется.

3. Что касается роли медиатора, на которую претендует Совет, то во французских редакциях такая должность существует с конца 80-х годов (по примеру США, где она возникла в 60-е годы) [7, c. 57]. Медиатор - это независимое физическое лицо, которое выступает посредником в урегулировании споров между редакцией и читателями, с целью достижения ими взаимоприемлемого решения и, тем самым, не доводить дела до суда. В настоящее время эта должность существует в восьми французских СМИ: France Médias Monde, France Télévisions, Le Monde, La Montagne, La Nouvelle République de Centre-Ouest (NRCO), Radio France, Sud Ouest et TF1, что говорит о том, что Совет дублирует уже существующую функцию.

4. Журналистское сообщество выражает сомнение по поводу возможности применения общей этики для всех видов СМИ, учитывая их большое количество (письменные, аудиовизуальные, веб-платформы) и разнообразие сфер их деятельности (общая, политическая, экономическая, специализированная пресса). По мнению автора книги «Право СМИ», профессора Эммануэля Дерьё, «такие условия журналистской деятельности, а также отношения журналистов с медиа-предприятиями до сих пор не позволяли им иметь общий этический кодекс и не похоже, чтобы эта ситуация изменилась» [3].

Выступая за плюрализм, журналистские профсоюзы видят свою задачу в том, чтобы защищать разнообразие подходов, а не соблюдать искусственный стандарт этики. «Журналистов должны судить читатели, а не собратья по перу» [16].

5. В итоге большое число профессионалов отказалось принимать участие в Совете. В этой связи он столкнулся с проблемой репрезентативности, которая в свою очередь поставила под сомнение его легитимность. Поэтому достижение цели - восстановление доверия аудитории к журналистам - оказалось тоже под угрозой. Если в Совет отказываются вступать именитые СМИ, как ему можно доверять?

Пути решения выхода из кризиса доверия, по мнению противников Совета, лежат в другой плоскости: для достойной журналистской деятельности необходимы нормальные условия труда, которые позволили бы журналистам не зависеть от воли акционеров медиа-предприятий и соответствовали бы французской концепции свободы.

\section{Деятельность Совета по деонтологии и медиации}

Несмотря на сильное противостояние журналистского сообщества, Совет по деонтологии и медиации функционирует уже более года. За это время поступило 390 обращений от общественности по 150 случаям нарушения журналисткой этики, из которых только 30 Совет счёл обоснованными, 100 - были отклонены, а 20 находятся на стадии рассмотрения.

Приведём в качестве примеров два заключения Совета и - главное -реакцию на них соответствующих СМИ.

Одним из первых нашумевших во Франции дел, рассмотренных Советом по деонтологии и медиации, стал случай оскорбления адвоката Жуан Бранко журналисткой Аполлин де Малерб во время интервью в прямом эфире телеканала BFMTV. За секунду до окончания передачи она назвала собеседника «манипулятором», не оставив ему времени для ответа. От телезрителей последовали 23 обращения, обвинявшие журналистку в отсутствии объективности и беспристраст- 
ности. Изучив суть вопроса, Совет вынес заключение: «когда журналист делает подобные заявления, то последнее слово он должен оставлять за интервьюируемым» [8]. После этого, согласно процедуре, представитель Совета попытался связаться с телеканалом BFMTV, но последний отказался от переговоров.

И это, кстати, далеко не единичный случай, когда СМИ, на которое поступила жалоба, категорически отказывается сотрудничать с Советом. Одно из последних заключений Совета по деонтологии датируется 26 марта 2021 года.

В Совет обратилась Инес Леро, журналист и автор комикса «Зелёные водоросли, запретная история» с жалобой на автора статьи Александра Бертолини «Зелёные водоросли и агропродовольственные товары: бретонские экоактивисты и теория заговора», опубликованной 13 июля 2020 года на сайте журнала Современные ценности (Valeurs actuelles). Автор статьи, ссылаясь на результаты расследования журналистки и цитируя её имя, не дал себе труда связаться с ней для перекрёстной проверки информации, в результате чего публикация содержит, на её взгляд, неточности и недостоверную информацию.

Совет счёл жалобу обоснованной, отметив, что «статья написана в жанре журналистского расследования, но при этом нарушает правила этого жанра, поскольку содержит личностные оценки, утверждения, не подкреплённые фактами. В статье есть непроверенная информация из анонимных источников, которая дискредитирует людей, чьи имена там фигурируют, и которым не была предоставлена возможность выразить свою точку зрения» [5].

После вынесения этого заключения Совет направил письмо директору издания Эрику Монжалусу, информирующее об обращении госпожи Инес Леро и предлагающее опубликовать заключение Совета, как это предусмотрено его уставом. Однако директор ответил, что «группа Валмонд (владелец журнала) не признает легитимности Совета по деонтологии. У него нет никакого права и прерогативы рассматривать или предъявлять нам претензии. Наша деятельность регламентируется французским законодательством и, в частности, законом 1881 года» [5].

Подводя итог нашему обзору, подчеркнём, что создание во Франции Совета по деонтологии и медиации, вызвав большой резонанс в журналистском сообществе, раскололо его на два лагеря, не равных как по своей численности, так и по популярности изданий, которые журналисты представляют. Симптоматично, что редакции большинства самых читаемых во Франции изданий оказались среди противников Совета, созданного по инициативе государства и им же частично финансируемого.

Таким образом, столкнувшись в современной политической ситуацией, с новыми вызовами, бо́льшая часть журналистского сообщества проявила недоверие к власти и показала своё стремление сохранять свободу прессы, завоёванную французским обществом ещё в XIX-ом веке.

(C) М.В. Тарасова, 2021

\section{Список литературы}

1. Бакштановский В.И. Этическая экспертиза идеи саморегулирования «медиацеха» // Саморегулирование журналистского сообщества. Опыт. Проблемы. Перспективы становления в России. 3-е изд., стереотип. М.: Галерия, 2004. 399 с.

2. Тарасова М.В. Журналистика по-французски. М.: Nestor Academic Publishers, 2016. 328 c.

3. actu-juridique.fr [Электронный ресурс] - 04.12.2019, URL: https://www.actu-juridique.fr/ntic-medias-presse/deontologiejournalistique-et-si-le-droit-suffisait/ (Дата доступа 25.07.2021)

4. cdjm.org [Электронный ресурc] - URL: https://cdjm.org/ (Дата доступа 20.07.2021)

5. cdjm.org [Электронный ресурс] Avis sur la saisine $\mathrm{N}^{\circ}$ 20-114, 26.03.2021. - URL: https://cdjm.org/avis-20-114/ (Дата доступа 27.07.2021)

6. contexte.com 29.11.2019 [Электронный ресурс] - URL: https://blog.contexte.com/conseil-de-deontologie-journalistiqueet-de-mediation-cdjm-pourquoi-f8c6ea5a8c72 (Дата доступа 20.07.2021)

7. Cros J.-J. Le Journalisme pour les Nuls. - Paris : Éditions First-Grund, 2011. 360 p.

8. Europe1.fr [Электронный ресурс] 27.05.2020 - URL: https://www.europe1.fr/medias-tele/comment-fonctionne-le-conseilde-deontologie-journalistique-et-de-mediation-cree-recemment-3971070 https://www.europe1.fr > medias-tele > commentfonction... (Дата доступа 28.07.2021) 
9. la-croix.com [Электронный ресурс] - URL: https://www.la croix.com/Economie/Medias/Barometre-medias-pourquoi-4Francais-10-boudent-linformation-2020-01-15-1201072072 (Дата доступа 18.07.2021)

10. la-croix.com [Электронный pecypc] - URL: https://www.la-croix.com/France/Deux-ans-gilets-jaunes-journalistesracontent-2020-11-13-1201124470 (Дата доступа 18.07.2021)

11. lexpress.fr 30.11.2019 [Электронный ресурс] - URL: https://www.lexpress.fr/actualite/medias/deontologie-les-journalistesse-dotent-de-leur-conseil-de-l-ordre_2109483.html (Дата доступа 18.07.2021)

12. legifrance.gouv.fr [Электронный ресурс] - URL: https://www.legifrance.gouv.fr/jorf/id/JORFTEXT000037847559/ (Дата доступа 18.07.2021)

13. legipresse.com $\mathrm{N}^{\circ} 373,9$ juillet 2019 [Электронный ресурс] - URL: https://www.legipresse.com/011-50293-la-federationinternationale-des-journalistes-propose-une-nouvelle-charte-mondiale-dethique.html (Дата доступа 11.06.2021)

14. lemonde.fr [Электронный ресурс] - URL: https://www.lemonde.fr/economie/article/2019/12/02/la-creation-d-un-conseilde-deontologie-des-medias-divise-la-profession_6021320_3234.html (Дата доступа 20.07.2021)

15. lesechos.fr [Электронный ресурс] - URL: https://www.lesechos.fr/tech-medias/medias/un-conseil-de-deontologie-desjournalistes-va-bien-voir-le-jour-1150640 (Дата доступа 8.05.2021)

16. mediapart.fr [Электронный pecypc] - URL: https://blogs.mediapart.fr/la-sdj-de-mediapart/blog/291119/conseil-dedeontologie-pourquoi-nous-n-y-participerons-pas (Дата доступа 20.08.2021)

\section{References}

1. Bakshtanovsky, V.I. Eticheskaia ekspertiza idei samoregulirovaniia mediatsekha [Ethic expertise of media workshop self regulation] // Samoregulirovanie zhurnalistskogo soobshhestva. Opyt. Problemy. Perspektivy stanovlenija v Rossii [Selfrugulation of journalist community. Experience. Problems. Perspectives of its formation in Russia]. 3-e izd., stereotip. M.: Galerija, 2004. $399 \mathrm{p}$.

2. Tarasova, M.V. Le journalisme à la française. M.: Nestor Academic Publishers, 2016. 328 p.

3. actu-juridique.fr [electronic resource] 04.12.2019, www.actu-juridique.fr/ntic-medias-presse/deontologie-journalistique-etsi-le-droit-suffisait/ (Accessed 25.07.2021)

4. cdjm.org [electronic resource], cdjm.org/ (Accessed 20.07.2021)

5. cdjm.org [electronic resource] Avis sur la saisine $\mathrm{N}^{\circ}$ 20-114, 26.03.2021, cdjm.org/avis-20-114/ (Accessed 27.07.2021)

6. contexte.com 29.11.2019 [electronic resource], blog.contexte.com/conseil-de-deontologie-journalistique-et-de-mediationcdjm-pourquoi-f8c6ea5a8c72 (Accessed 20.07.2021)

7. Cros, J.-J. Le Journalisme pour les Nuls. Paris: Éditions First-Grund, 2011. 360p.

8. Europe1.fr [electronic resource] 27.05.2020, www.europe1.fr/medias-tele/comment-fonctionne-le-conseil-de-deontologiejournalistique-et-de-mediation-cree-recemment-3971070 https://www.europe1.fr , medias-tele , comment-fonction... (Accessed 28.07.2021)

9. la-croix.com [electronic resource], croix.com/Economie/Medias/Barometre-medias-pourquoi-4-Francais-10-boudent-linfor mation-2020-01-15-1201072072 (Accessed 18.07.2021)

10. la-croix.com [electronic resource], www.la-croix.com/France/Deux-ans-gilets-jaunes-journalistesracontent-2020-11-13-1201124470 (Accessed 18.07.2021)

11. lexpress.fr 30.11.2019 [electronic resource], www.lexpress.fr/actualite/medias/deontologie-les-journalistes-se-dotent-de-leurconseil-de-l-ordre_2109483.html (Accessed 18.07.2021)

12. legifrance.gouv.fr [electronic resource], www.legifrance.gouv.fr/jorf/id/JORFTEXT000037847559/ (Accessed 18.07.2021)

13. legipresse.com $\mathrm{N}^{\circ} 373,9$ juillet 2019 [electronic resource], www.legipresse.com/011-50293-la-federation-internationale-desjournalistes-propose-une-nouvelle-charte-mondiale-dethique.html (Accessed 11.06.2021)

14. lemonde.fr [electronic resource], www.lemonde.fr/economie/article/2019/12/02/la-creation-d-un-conseil-de-deontologiedes-medias-divise-la-profession_6021320_3234.html (Accessed 20.07.2021)

15. lesechos.fr [electronic resource], www.lesechos.fr/tech-medias/medias/un-conseil-de-deontologie-des-journalistes-va-bienvoir-le-jour-1150640 (Accessed 8.05.2021)

16. mediapart.fr [electronic resource], blogs.mediapart.fr/la-sdj-de-mediapart/blog/291119/conseil-de-deontologie-pourquoinous-n-y-participerons-pas (Accessed 20.08.2021)

\section{Сведения об авторе:}

Тарасова Мария Вячеславовна - кандидат филологических наук, доцент кафедры французского языка МГИМО МИД России. Сфера научных и профессиональных интересов: французский медиадискурс, грамматика французского языка, французская журналистика, жанры французской прессы.

E-mail: maria.tarassova@gmail.com

\section{About the author:}

Maria V. Tarasova - PhD in Philology, Associate Professor, French Department, MGIMO-University. Spheres of research and professional interest: media discourse, French grammar, French journalism, genres in French journalism. E-mail : maria.tarassova@gmail.com

$* * *$ 